\title{
Embedding boron into Ti powder for direct laser deposited titanium matrix composite: microstructure evolution and the role of nano-TiB network structure
}

\author{
Minhan Fanga, Yuanfei Han ${ }^{\mathrm{a}, \mathrm{b}, *}$, Zhusheng Shi ${ }^{\mathrm{c}}$, Guangfa Huanga \\ Jingwen Song ${ }^{\mathrm{a}}$, Weijie $\mathrm{Lu}^{\mathrm{a}, \mathrm{b}, *}$ \\ ${ }^{a}$ State Key Laboratory of Metal Matrix Composites, School of Material Science and \\ Engineering, Shanghai Jiao Tong University, Shanghai, 200240, PR China \\ ${ }^{\mathrm{b}}$ Shanghai Key Laboratory of Advanced High Temperature Materials and Precision \\ Forming, Shanghai 200240, PR China \\ ${ }^{c}$ Department of Mechanical Engineering, Imperial College London, London SW7 2AZ, \\ UK \\ *Corresponding authors:
}

Tel.: +86-21-34202641; Fax: +86-21-34202749

E-mail addresses: hyuf1@sjtu.edu.cn (Y. Han), luweijie@sjtu.edu.cn (W. Lu)

\begin{abstract}
:
The titanium powder embedded with $2.5 \mathrm{vol} \% \mathrm{TiB}$ was in-situ fabricated by gas atomization and applied for direct laser deposited (DLD) titanium matrix composites. Consistent with the network distributed boron-rich zone in composite powder, a threedimensional (3D) in-situ ultrafine network structure, consisting of nano-TiB whiskers (TiBw), was characterized throughout the as-fabricated composite (DLDed TiB-Ti). Both the dendritic and equiaxed network, attributed to the boron-induced constitutional supercooling and subsequent nucleation and growth of primary $\beta$-Ti, existed in the composite. The addition of boron (B) had a positive effect on the equiaxial transition and grain refinement of both primary $\beta$-Ti grains and $\alpha$ grains. Tensile tests showed an enhancement of strength compared with conventionally fabricated homogeneous TiB-Ti composites and selective laser melted CP-Ti. Analyzing the strength mechanism of the DLDed TiB-Ti, apart from the fine-grain strengthening and load-bearing effect of TiBw, the TiB network was found to have an additional contribution to the improvement of strength. Fracture morphology and in situ tensile observation showed the role of network structure in plastic deformation limitation, crack deflection and blunting, which was mainly attributed to the ultrafine cell size and revealed the significance of network structure.
\end{abstract}

Keywords: Titanium matrix composite; direct laser deposited; nano-sized TiB; network structure; mechanical properties. 


\section{Introduction}

Titanium matrix composites (TMCs) play an increasingly important role as structural materials in the automotive and aerospace fields [1,2], due to the excellent specific strength, good corrosion resistance, outstanding specific modulus, terrific hightemperature strength, and high biocompatibility $[3,4]$. Conventional preparation methods of Ti-based materials, mainly based on the in-situ reaction between matrix and specific reactant for the synthesis of reinforcements, include casting and powder metallurgy. The casting technique possesses potential in preparing big ingots, and systematical research about casted TMCs homogenously reinforced with $\mathrm{TiB}[5,6]$, TiC [7] and $\mathrm{La}_{2} \mathrm{O}_{3}[8,9]$ et al. had been reported with the addition of $\mathrm{TiB}_{2}, \mathrm{~B}_{4} \mathrm{C}$, and $\mathrm{LaB}_{6}$, etc. Besides, despite the higher cost and the inability to produce large ingots compared to casting, powder metallurgy has a distinct advantage in the design of the inhomogeneous distribution of reinforcement, such as a $3 \mathrm{D}$ quasi-continuous reinforcement-rich network to achieve improvements in strength $[10,11]$. Despite the remarkable comprehensive properties, the applications of TMCs have always been limited by the difficulty of plastic working and thus the high cost of post-processing [12]. Because of the low thermal conductivity, active chemical affinity, and existence of hard reinforcements, the subsequent processing may lead to a large amount of feedstock material waste, as well as unwanted by-products and defects $[13,14]$.

Recently, additive manufacturing (AM) of metals has been rapidly developed due to its capability of three-dimensional near-net forming of complex components [15]. Hence, AM techniques in TMCs have attracted more and more attention. Attar et al. [16] 
fabricated titanium-titanium boride composites via selective laser melting (SLM) and the composite showed significant compressive strength improvement compared with SLMed CP-Ti. Furthermore, direct laser deposited (DLD), also known as laser engineered net shaping (LENS) or laser solid forming (LSF), is also applied for the preparation of TMCs. Hu et al. [17] combined the design of inhomogeneous reinforcements and AM technique, and successfully fabricated TiB-Ti composites with 3D quasi-continuous network microstructure, which showed remarkable compression and wear properties. For the aforementioned powder-based AM techniques, the traditional preparation method of the raw powder is the mixing of metal powder and ceramic powder, such as using ball milling $[16,18]$. However, several shortcomings of mechanical blending have been noticed with the mixed powder. The reinforcement size varies from nanometers to microns, and the particles are mostly irregular in shape, which induces deteriorating flowability of the powders [19]. Moreover, the ceramic powder generally has a much higher melting point compared to the metal powder and is difficult to be completely melted $[19,20]$, and thus the thermal behavior of molten pool is complex and difficult to predict due to the variation of laser absorptivity between metal and ceramic powder [21]. Therefore, fabricating defect-free and highly dense titanium composites requires specifically optimized processes by designing reinforcements, content, and morphology, etc. [22, 23].

Recently, several studies reported a new approach to prepare raw powder [24, 25]. Li et al. [24] designed an in-situ nano-TiB 2 decorated AlSi10Mg powder by gas atomization for selective laser melting and fully dense nano- $\mathrm{TiB}_{2}$ decorated $\mathrm{AlSi} 10 \mathrm{Mg}$ alloy was successfully fabricated with high fracture strength and ductility. Mahbooba et al. [25] pre- 
alloyed Ti-6Al-4V powder with boron to fabricate bulk samples via electron beam additive manufacturing, the micro-hardness and strength of the fabricated samples were sharply enhanced by increasing boron element which also induced a significant refinement of $\alpha$ grains. As investigated in previous works, the composite powder produced from prefabricated composite ingots could avoid the shortcomings of mechanical blending and had a positive effect on their performance.

In this study, nano-TiB embedded Ti-based powder with an ultrafine network was produced by gas-atomization from prefabricated TiB-reinforced pure Ti matrix composite ingot and applied for direct laser deposition. 2.5vol\% TiB reinforced Ti composite with a novel in-situ quasi-continuous ultrafine network structure was fabricated. The microstructure morphology and tensile properties were detailly evaluated. Moreover, the formation and evolution mechanism of the in-situ network and the strengthening effect of network distributed nano-TiB whiskers were systematically studied.

\section{Material and methods}

\subsection{Fabrication of Ti-based powder embedded with TiB}

Firstly, sponge titanium $(>99.9 \%)$ and $\mathrm{TiB}_{2}$ powder $(>99.5 \%,<5 \mu \mathrm{m})$ were mixed and compressed into consumable electrodes to fabricate $2.5 \mathrm{vol} \% \mathrm{TiB}$ reinforced pure $\mathrm{Ti}$ matrix composite ingot via melting three times in a consumable-electrode vacuum arcmelting furnace to make sure the in-situ reaction completely proceeded, and the produced TiB whiskers (TiBw) were distributed homogeneously. The equivalent atomic percentage of boron was $2.0 \%$. Then the casting ingot was forged and machined to meet the size 
requirement of powder manufacturing equipment. The composite powders were produced via gas atomization (EIGA 50, ALD, Germany), and the gas atomized composite powders with a particle size of $53-150 \mu \mathrm{m}$ were used for the direct laser deposited processing.

\subsection{Processing parameters}

TiB-Ti composite sample with dimensions of $70 \times 30 \times 40 \mathrm{~mm}(\mathrm{~L} \times \mathrm{W} \times \mathrm{H})$ was fabricated by a direct laser deposited (DLD) platform (RayCham LDM-8060) containing a Ytterbium laser system, a three-axis $\mathrm{CNC}$ machine, and a coaxial powder feeding equipment under argon atmosphere. The processing parameters used were as follows: laser power $1500 \mathrm{~W}$, scanning speed $10 \mathrm{~mm} / \mathrm{s}$ ( 120 seconds per layer), powder feeding rate $\sim 0.074 \mathrm{~g} / \mathrm{s}, \mathrm{Z}$-axis increment $0.7 \mathrm{~mm}$, oxygen level $<50 \mathrm{ppm}$, laser beam diameter $3 \mathrm{~mm}$ and hatch distance $1.7 \mathrm{~mm}$. Fig. 1a shows the schematic of the DLDed TiB-Ti composite, including a coordinate with width direction $(\mathrm{X})$, length direction $(\mathrm{Y})$ and height direction (Z), S-shaped scanning strategy, and sampling orientation for tensile tests.

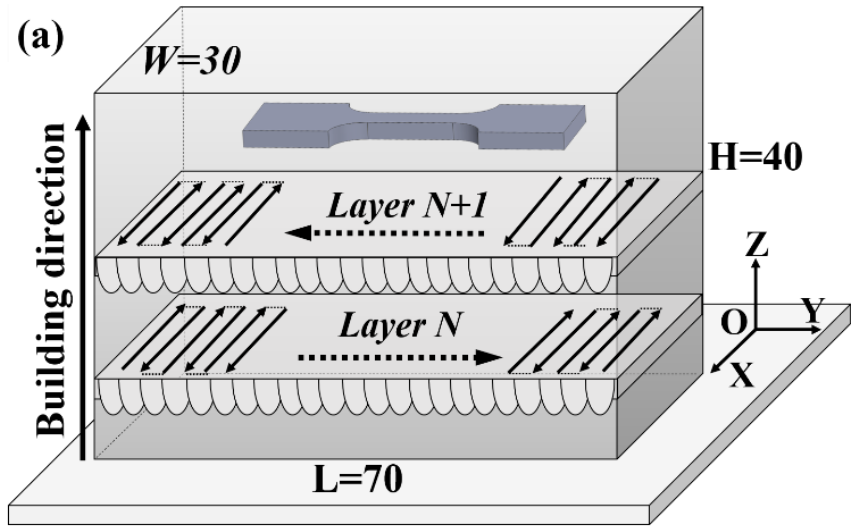

(b)

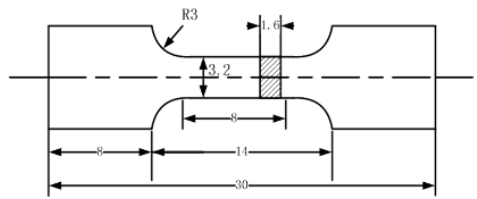

(c)

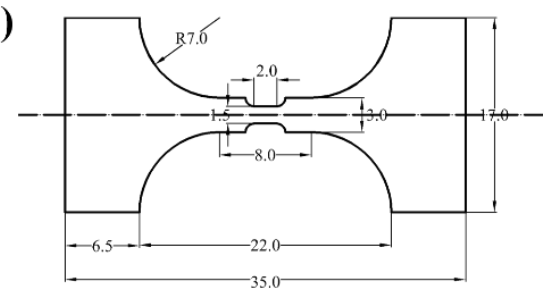

Fig. 1. (a)Schematic of the DLDed process, including scanning strategy, tensile sampling, and coordinates; (b) the tensile test specimen; (c) the in-situ tensile test specimen. (Unit: $\mathrm{mm}$ )

\subsection{Microstructure characterization and mechanical property}


The XRD test was conducted on a Mini Flex600 machine (Rigaku Corp., $\mathrm{Cu}$ Ka target, $40 \mathrm{kV}, 15 \mathrm{~mA}$ ) with a step size $0.02^{\circ}$ and a scanning speed of $2 \% \mathrm{~min}$ on the XOY plane. Microstructure characterization was performed on an FEI NOVA NanoSEM 230 scanning electron microscope (SEM) equipped with Energy-dispersive spectroscopy (EDS) detector and Electron backscatter diffraction (EBSD) test system, and a JEM-2100 transmission electron microscope (TEM). EBSD was conducted with a step size of 0.35 $\mu \mathrm{m}$ and the data analysis was performed on HKL Channel 5 (Oxford Instrument) software package. The composite powders attached to the conductive tape or embedded in conductive resin were used to analyze the morphology and microstructure. The SEM samples were mechanically ground, polished, and etched by a mixture of $1 \mathrm{ml} \mathrm{HF}+3 \mathrm{ml}$ $\mathrm{HNO}_{3}+10 \mathrm{ml} \mathrm{H} \mathrm{H}_{2} \mathrm{O}$. EBSD samples were prepared by electrochemical polishing with a mixture of $4 \mathrm{ml} \mathrm{HClO}_{4}$ and $96 \mathrm{ml} \mathrm{CH}_{3} \mathrm{COOH}$ under a direct current voltage of $60 \mathrm{~V}$. TEM samples were mechanically thinned and prepared by twin-jet polishing. The flat dog-bone samples with a gauge length of $8 \mathrm{~mm}$ and a thickness of $1.6 \mathrm{~mm}$, as shown in Fig $1 \mathrm{~b}$ were cut parallel to the XOY plane and mechanically polished before stretched along Y-axis. Mechanical properties were tested on an Instron 5966 universal testing machine at a strain rate of $1 \times 10^{-3} \mathrm{~s}^{-1}$. The in-situ tensile test was conducted on a Zeiss Supra 55 SEM equipped with a Gatan Mtest5000S module using a constant crosshead speed of $0.1 \mathrm{~mm} / \mathrm{min}$. The size drawing of the in-situ tensile specimen is shown in Fig. 1c, and the samples were mechanically polished and etched before the tensile test. 


\section{Results}

\subsection{Microstructure of composite powder}

Fig. 2 shows the morphology of the gas atomized TiB-Ti composite powders. All composite powders showed nice sphericity and good flowability. No broken or hollow particles were found and the surfaces were smooth, a few satellite particles existed on the powder particles. Fig. $2 \mathrm{~b}$ presents a fine equiaxed network distribution throughout the cross-section in an ultrafine cell size of $2 \sim 10 \mu \mathrm{m}$ and Fig. $2 \mathrm{c}$ shows the high magnification image of the nearly equiaxed cells and the "skeleton" of network structure, which consisted of ultrafine clustered needles. Fig. $2 \mathrm{~d}$ shows the line scanning profile of Ti and B with EDS. Titanium was detected throughout the line with a relatively lower content at the skeleton of the network. Although the EDS test is not quantitatively accurate about boron element, the detection result could qualitatively indicate that boron was richly distributed at the skeleton and almost none inside the cells. According to the binary phase diagram of $\mathrm{Ti}$ and $\mathrm{B}$, as the content of $\mathrm{B}$ is far less than the eutectic composition and the reaction is complete, only $\mathrm{TiB}$ exists in the system. Moreover, the high magnification image (Fig. 2c) shows that the network was composed of ultrafine clustered needles. Thus, the network consisted of ultrafine nano-TiB. Over the reported work, a similar method has already been applied to produce composite powder, where it was called pre-alloy TiB powder [26, 27]. Applied to the powder metallurgy (PM), this approach was proven to form nanometer-sized $\mathrm{TiB}$ precipitates which were much finer than that produced by blended element powder compact. Hence, the TiB-Ti composite powder with good morphology and flowability offered a solid foundation for the DLDed TiB-Ti composite. 

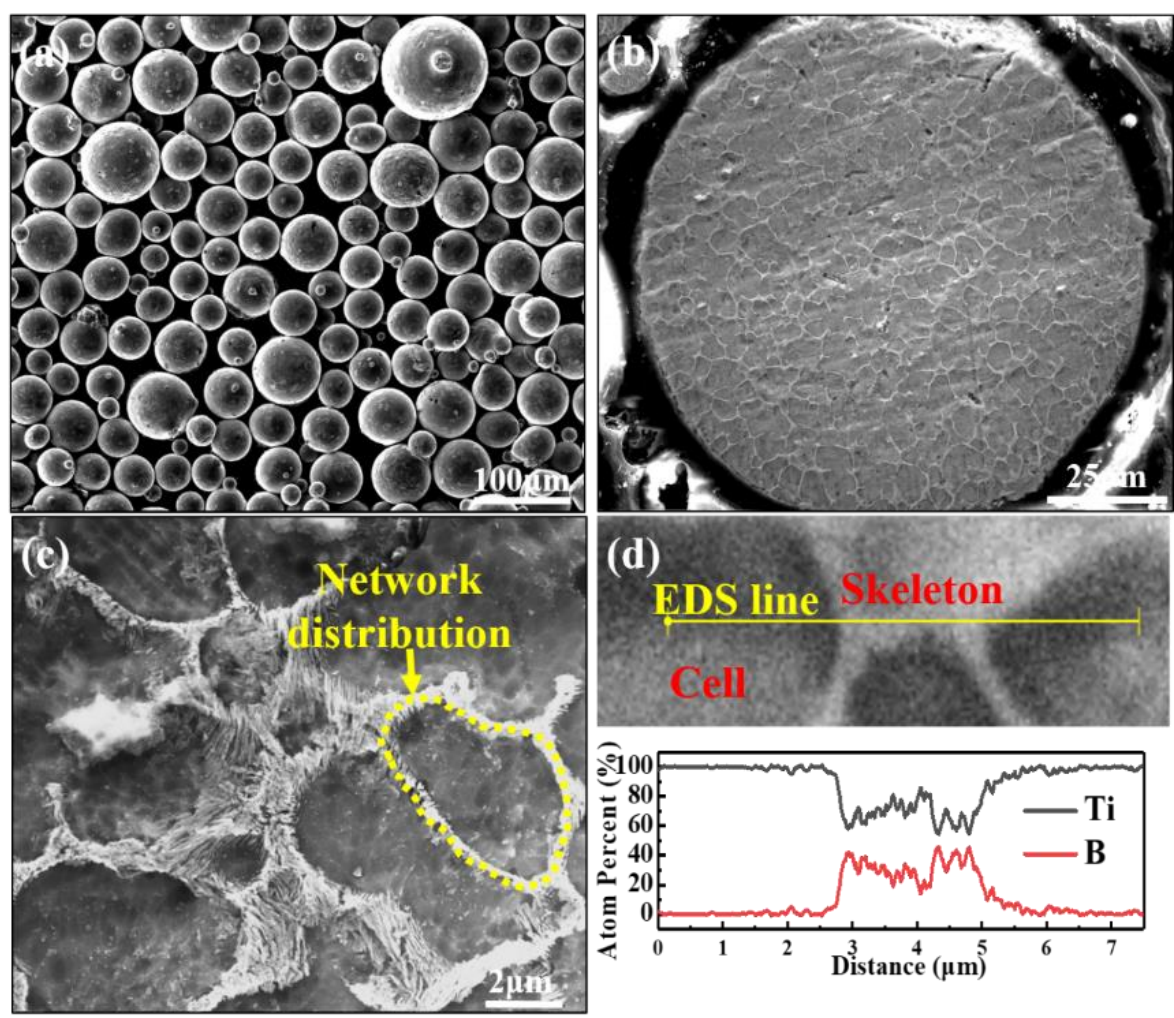

Fig. 2. The SEM images of (a) particle morphology, the cross-section in (b) low and (c) high magnification, and (d) EDS line profile of the composite powder.

\subsection{Microstructure of the DLDed TiB-Ti}

The XRD analysis of the composite powder and DLDed sample is shown in Fig. 3. No apparent difference was observed in the XRD spectrums between the composite powder and the DLDed sample. It was concluded that both the composite powder and DLDed TiB-Ti consisted of $\alpha$-Ti matrix and TiB. According to the [ $\alpha-\mathrm{Ti} \# 44-1294$ ] in XRD database and Ref $[28,29]$, the following crystal planes had nearly identical interplanar spacing $d: d(10 \overline{1} 0)_{\alpha-\mathrm{Ti}}=d(201)_{\mathrm{TiB}}, d(0002)_{\alpha-\mathrm{Ti}}=d(201)_{\mathrm{TiB}}$, and $d(20 \overline{2} 0)_{\alpha-\mathrm{Ti}}=d(112)_{\mathrm{TiB}}$, which led to the overlapping of diffraction peaks. The enlarged image showed the minor difference of the two peaks from 41 43 $2 \theta$ degrees, which was probably due to the incomplete precipitation of $\mathrm{TiB}$ under the more rapid cooling rate in the gas-atomization process compared to that in the DLD process. 


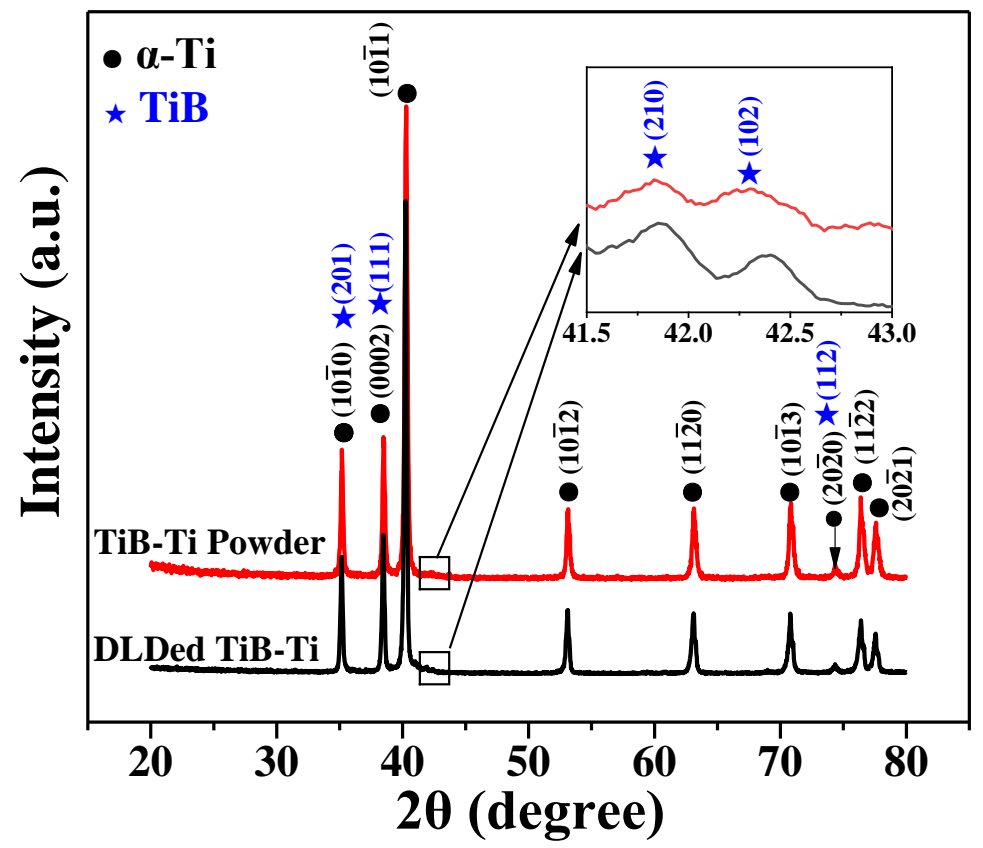

Fig. 3. XRD spectrums of the TiB-Ti composite powder and the DLDed TiB-Ti

Fig. 4 shows the microstructure of the DLDed TiB-Ti composite, where the white area is TiBw and the dark area is the $\alpha$-Ti matrix. No defects and pores were observed in the whole specimen. The DLDed TiB-Ti sample showed a quasi-continuous equiaxed network and the average cell size was measured as $9.04 \mu \mathrm{m}$ by the linear interception method (Fig. 4a) in the XOY plane. Clustered nano-TiBw built the novel network microstructure (Fig. 4b), which shows a trigeminal cell boundary consisted of two clusters of nano-TiBw. The TiBw belonging to one cluster were approximately parallel and arrayed along the cell boundary, it shows different morphology of needle-like and platelike whiskers.

In Fig. 4c (YOZ view), the arcuate contour of the molten pool separating the layer $\mathrm{N}$ and layer $\mathrm{N}+1$ could be identified, as marked by a yellow dashed line. Heterogeneous TiBw network structures alternately distributed along the Z-axis, which included the 
equiaxed structure and dendritic network structure, respectively. To regard the molten pool contour as the centerline, the dendritic network distributed on both sides with a size less than $150 \mu \mathrm{m}$, i.e. the dendritic network distributed either at the bottom or top of the molten pool and occupied only a small portion of a deposited layer (layer thickness was set as $0.7 \mathrm{~cm}$ ). Similar to the $\mathrm{YOZ}$ view, ordered and heterogeneous microstructures were also observed along the Z-axis in the $\mathrm{XOZ}$ view (Fig. 4d). A high magnification image showed the morphology of the dendritic structure (Fig. 4e). The columnar primary $\beta$-Ti grain could be identified and was the primary dendrite arm. Perpendicular to the columnar primary grain, secondary dendrite arms distributed parallel to the $\mathrm{X}$-axis. The nano-TiBw distributed in the interdendritic region.

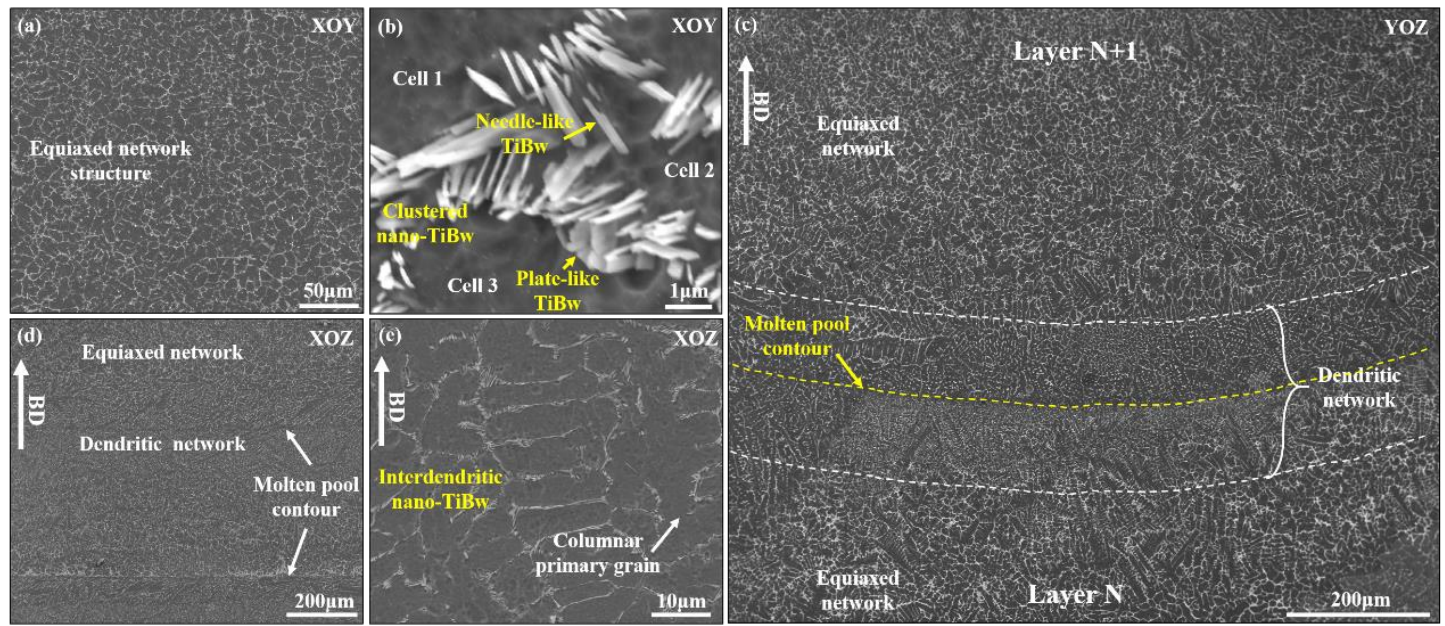

Fig. 4. The microstructure of the DLDed TiB-Ti sample. (a-b) XOY section, (c) YOZ section, and (d-e) XOZ section.

The TEM images and the corresponding selected area electron diffraction (SAED) patterns of the DLDed TiB-Ti are shown in Fig. 5. Multiple TiB whiskers (nano-TiBw), which was of $\sim 100 \mathrm{~nm}$ in thickness and several microns in length, could be identified in the $\alpha$-Ti matrix (Fig. 5a). The typical crystallographic structure of TiBw, which was 
named B27 structure, in casting titanium matrix composites has already been reported by Lu et al $[5,30]$. The B27 structure of TiBw had a preferential growth along the [010] direction leading to a needle-like morphology (Fig. 5b) with a hexagonal cross-section. The interface between TiB and Ti matrix was flat and sharp (Fig. 5c) offering the good ability of stress transfer due to the minor difference of coefficient of thermal expansion [31] and the in-situ synthesis mechanism.

Fig. $5 \mathrm{~d}$ shows the cross-section view of a TiB whisker with a plate-like shape and a faceted interface between $\mathrm{TiB}$ and Ti matrix. The corresponding fast Fourier transform (FFT) pattern in Fig. 5e reveals both the B27 and $\mathrm{B}_{\mathrm{f}}$ structure of TiBw, as well as the orientation relationship of $\mathrm{B} 27$ [010] // $\mathrm{B}_{\mathrm{f}}[001]$ and $\mathrm{B} 27(200) / / \mathrm{B}_{\mathrm{f}}(110)$. The highresolution (HR) TEM image showed a flat interface between $B 27$ and $B_{f}$, and plenty of stacking faults. Compared to the B27 structure, $\mathrm{B}_{\mathrm{f}}$ was in a metastable state and less favorable in growth kinetics, hence the as-cast TiB structure was B27 [32] under the cooling process close to an equilibrium condition. However, the fast cooling characteristics of the DLD process gave rise to the variation of TiB structure. Kooi et al. [33] reported that, in a laser-clad TiB-Ti coating, $\mathrm{B}_{\mathrm{f}}$ structure mostly existed in the platelike and fine needle-like TiB due to the eutectic transition as the TiB grew cooperatively with the solid $\mathrm{Ti}$ under the conditions of rapid cooling. In this study, the system composition was in the hypoeutectic field (boron content was 2.0 at $\%$ ) of the Ti-B phase diagram, i.e. no primary $\mathrm{TiB}$ formed before the eutectic transformation, which was consistent with the reported mechanism in Ref[33]. Moreover, the change of crystallographic structure led to a variety of preferential growth direction, giving rise to 
the faceted interface and plate-like morphology. Besides, the perfect fitness of B27(200) // Bf(110) easily resulted in stacking disorder, especially under the residual stress induced by rapid cooling. Fig. $5 \mathrm{f}$ shows another TiBw in cross-section view. The observed TiBw had more equiaxed cross-sections compared with that in Fig. 5d. Notably, a whisker with a typical hexagonal cross-section and without any stacking faults was observed, which was more likely to be an exact B27 structure. At last, the TEM analysis could not serve as a quantitative method for the counting of $\mathrm{B}_{\mathrm{f}}$ structure, which was probably the reason why the existence of $\mathrm{B}_{\mathrm{f}}$ structure was not detected in the XRD spectrum.
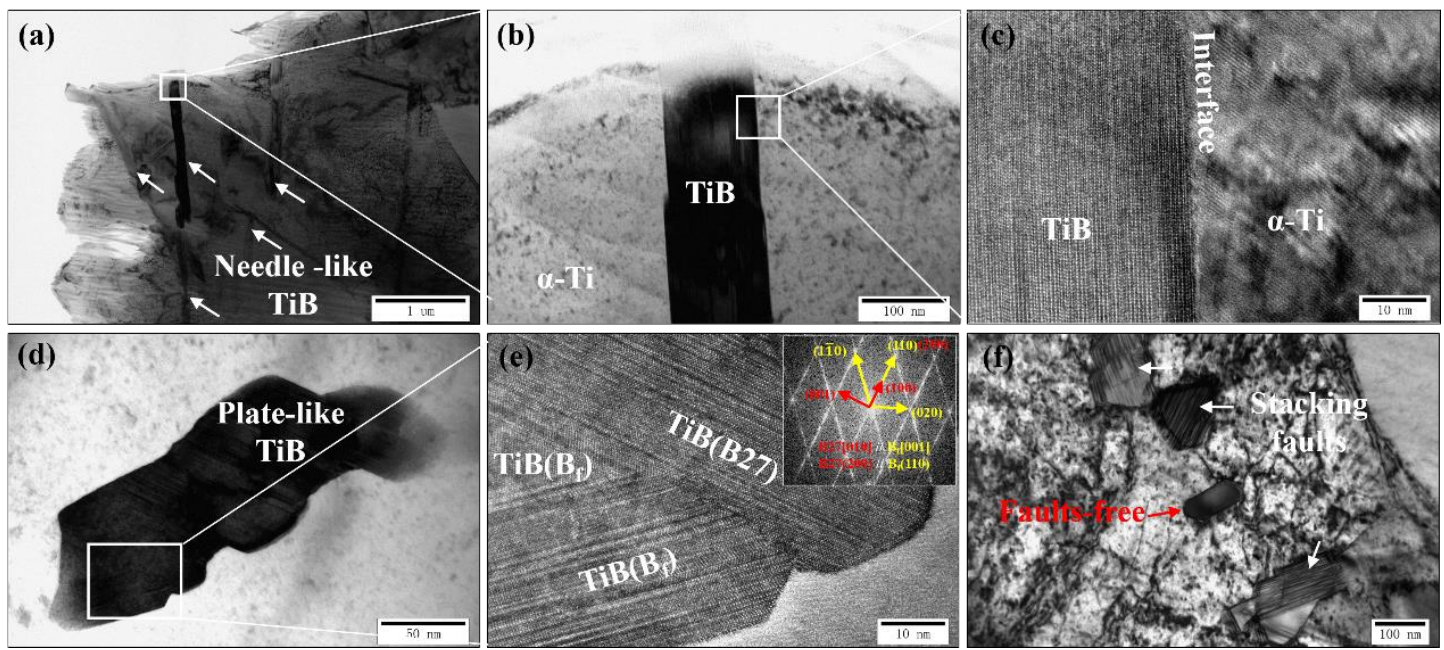

Fig. 5. (a-b) Bright-field TEM images of the nano-sized TiB whisker; (c) highresolution (HR) TEM image of the TiB-Ti interface; (d) plate-like TiB; (e) HRTEM image of the plate-like TiB and the corresponding fast Fourier transform (FFT) pattern indicating B27[010] // $\mathrm{B}_{\mathrm{f}}[001]$ and $\mathrm{B} 27(200) / / \mathrm{B}_{\mathrm{f}}(110)$; (f) cross-section view of TiBw.

\subsection{Tensile properties and fracture morphology}

The engineering stress-strain curve of the tested DLDed TiB-Ti composite is presented in Fig. 6a. The sample had a yield strength (YS) of $479 \mathrm{MPa}$, an ultimate tensile strength (UTS) of $636 \mathrm{MPa}$, and an elongation (EI) of 10.6\%. The comparison of tensile properties 
with other homogeneously reinforced pure Ti matrix composites is shown in Fig. 6b, including spark plasma sintered (SPS) 1.2/2.4 wt\% TiB 2 -Ti [34], powder metallurgy (PM) pure $\mathrm{Ti}$ and 8.5 vol\% TiB-Ti $[35,36]$, laser melting deposition (LMD) 10/20 vol\% TiC-Ti [37], and casting $1.5 \mathrm{wt} \% \mathrm{~B}-\mathrm{Ti}$ [38]. The DLDed TiB-Ti composite showed a comparable or higher combination of strength and ductility than the homogeneously reinforced TMCs.

Fig. 7 shows the representative fracture surfaces of the DLDed TiB-Ti tensile sample. The co-existing dimples and tearing ridges that were marked by yellow and red arrows respectively (Fig. $7 b$ ) occupying the most area, which was due to the deformation and fracture of the Ti matrix. Besides, tearing zones consisting of closely clustered tearing ridges, which were different from the tearing ridges encircling the dimples, were observed in the regions highlighted by white dotted lines in Fig. $7 \mathrm{~b}$ and the high magnification image in Fig. 7c. As mentioned earlier in this study, the network structure was composed of clustered nano-TiBw. The morphology of the clustered tearing ridges was consistent with the size and distribution of the nano-TiBw clusters.
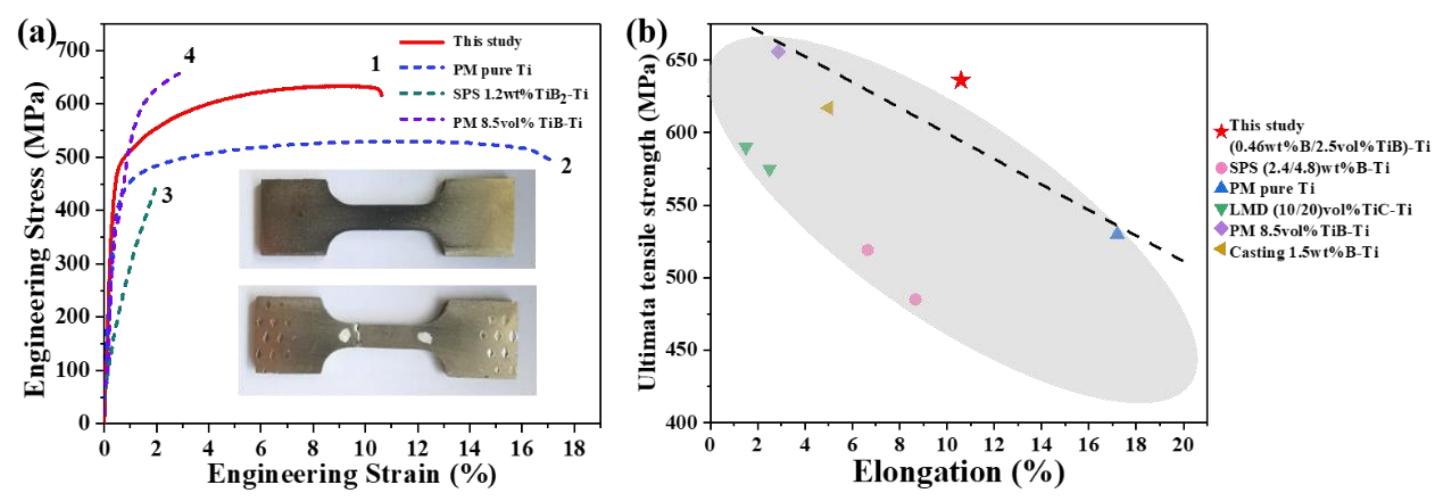

Fig. 6. The comparison of tensile properties of this study with other pure Ti matrix composites. 


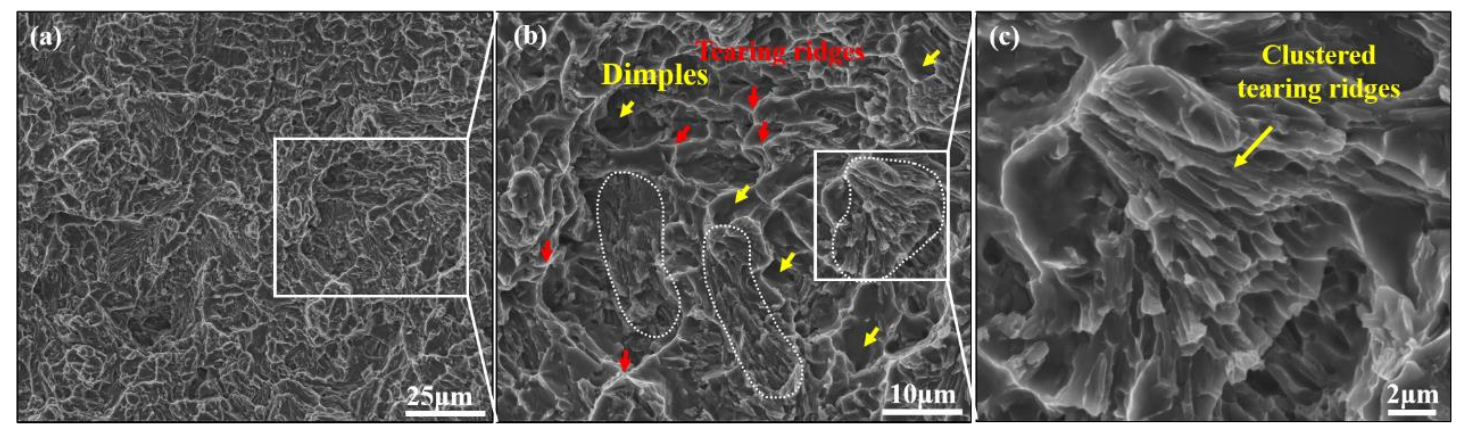

Fig. 7. Representative fracture morphologies of the DLDed TiB-Ti tensile sample.

\section{Discussion}

\subsection{The formation mechanism and morphology evolution of network structure.}

The Ti-B binary phase diagram is presented in Fig. 8. (the atomic percentage of boron was from $0 \%$ to $50 \%$ for clarification). The boron content at the eutectic point is approximate $6.7 \mathrm{at} \%(8.5 \mathrm{vol} \% \mathrm{TiB})$. If the boron content is higher than eutectic, the solidification process is as follows: Liquid $\rightarrow$ Liquid + primary $\mathrm{TiB} \rightarrow$ primary $\mathrm{TiB}+$ eutectic $(\mathrm{TiB}+\beta \mathrm{Ti})$. The primary precipitation of $\mathrm{TiB}$ leads to a coarse morphology, which may deteriorate the mechanical property. Besides, the high content of the ceramic phase may lead to the lack of fusion in the gas-atomization process and additive manufacturing process $[23,39]$. Hence, a hypoeutectic composition $(2.5 \mathrm{vol} \%$ TiB or $2.0 \mathrm{at} \%$ boron) was selected in this study, as marked in Fig. 8. Moreover, the composite ingot was melted three times so that the TiBw distributed homogeneously to ensure the successful production of composite powder. Both the parameters of gas atomization and additive manufacturing were optimized for titanium. As presented in Fig. 2, the particle morphology of the composite powder showed nice sphericity and the boron-rich zone was homogeneous in the macro-scale in the powder, indicating the nice applicability of this study. 


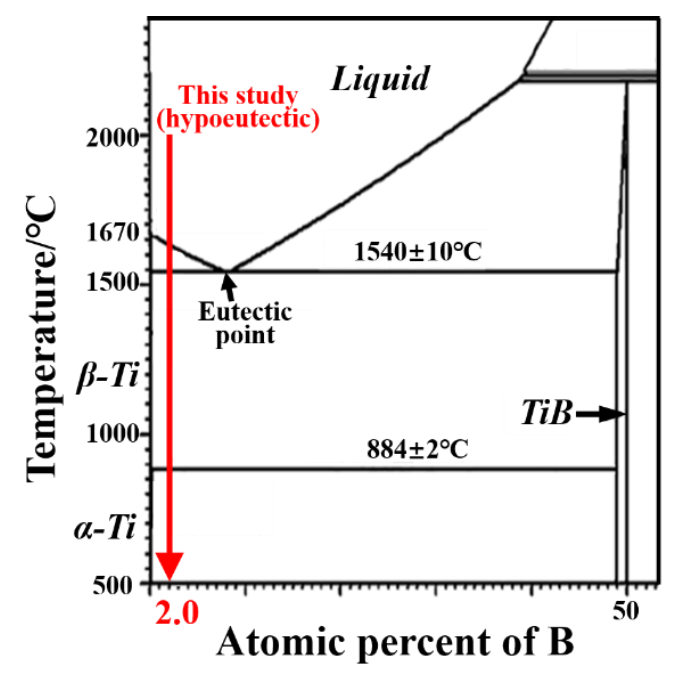

Fig. 8. Ti-B phase diagram (the equivalent atomic percentage was $2.0 \%$ ).

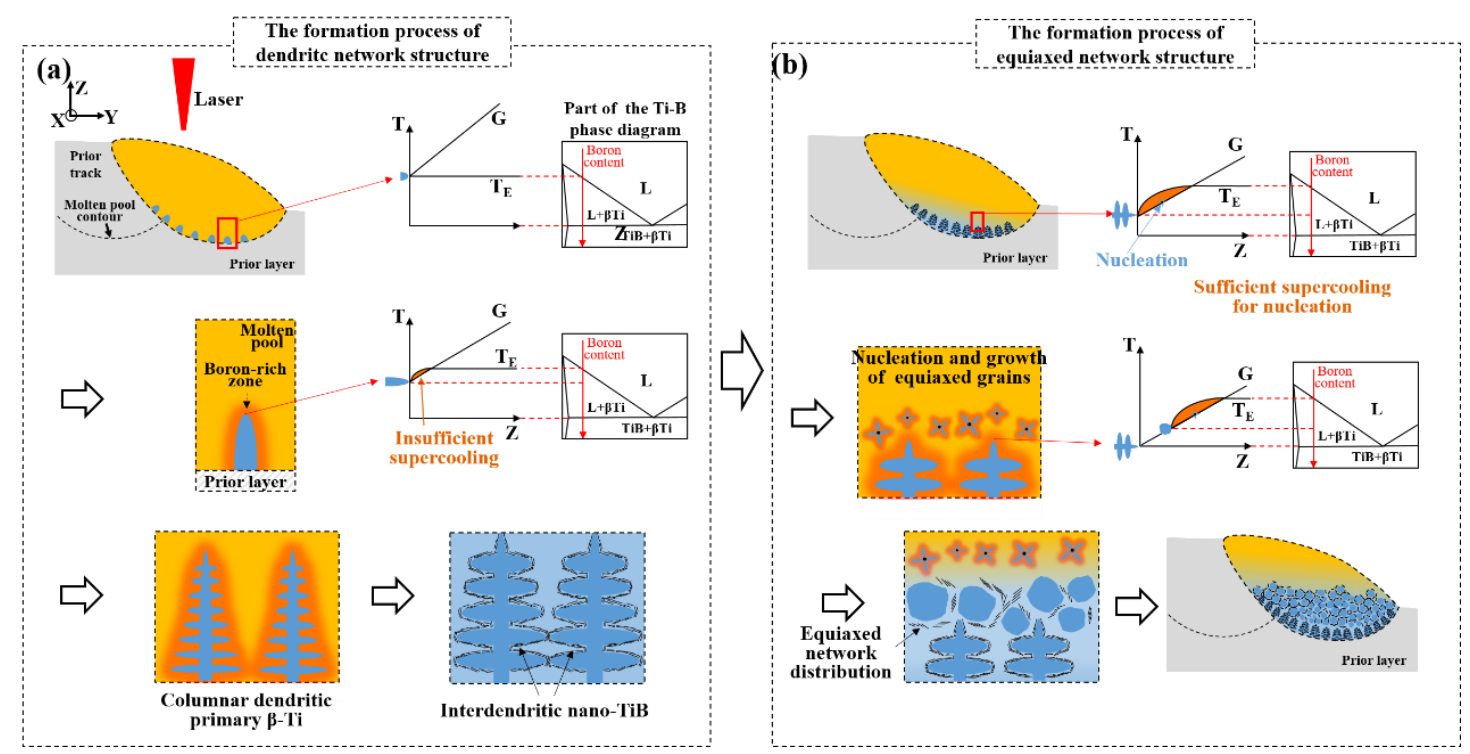

Fig. 9. Schematic of the formation process of (a) dendritic network distribution and (b) equiaxed network distribution of nano-TiBw

As illustrated in the phase diagram of Fig. 8, the solidification process in this study follows the sequence: Liquid $\rightarrow$ Liquid + primary $\beta \mathrm{Ti} \rightarrow$ primary $\beta \mathrm{Ti}+$ eutectic $(\mathrm{TiB}+$ $\beta$ Ti). Since the solid solubility of boron in $\beta$ Ti was negligible, nearly all the boron was expelled out of the primary $\beta \mathrm{Ti}$ grains. As the temperature dropped to eutectic temperature, the concentration of boron in the remaining liquid rose to the eutectic point, and finally, eutectic $(\mathrm{TiB}+\beta \mathrm{Ti})$ formed. Fig. 12 schematically presents the formation 
process of the dendritic network distribution and equiaxed network distribution coherently in chronological order in the YOZ view. The jetted powder melted and then formed a molten pool consisting of Ti and dissolved TiB during laser scanning. As widely reported, the instantaneous high energy input created an extremely steep temperature gradient $(G)$ enabling Marangoni effects [40], which meant complex fluid convection within the molten pool and was believed to rearrange the distribution of reinforcements [41]. At the bottom of the molten pool, as the temperature reached liquidus, the first batch of primary $\beta$ Ti grains nucleated, and the curve of equilibrium solidification temperature $\left(T_{E}\right)$ was flat (Fig. 9a). As the primary $\beta$ Ti grains grown, boron was continued to be rejected into the liquid, producing boron partitioning ahead of the solidification front. The enrichment of boron decreased the liquidus temperature resulting in a constitutional supercooling (CS) zone [42], which offered an overlapping area between the curves of $G$ and $T_{E}$. For the Ti-B binary system, the development of CS could be expressed by the Maxwell and Hellawell model [43]: $Q=m(k-1) C_{0}$, where $Q$ was the growth restriction factor, $m$ was the slope of the liquidus, $k$ was the solute partition coefficient, and $C_{0}$ was the solute content. The calculation result of $m(k-1)$ was $66[44,45]$ in the Ti-B system and hence boron was one of the most powerful elements to develop a strong supercooling zone. However, in the early stage of solidification, $G$ was still steep and the convection was strong. As a consequence, the expelled boron was partly transported away from the solid/liquid interface, weakening the solute enrichment. Hence, the overlapping area (the second phase diagram in Fig. 9a) was narrow. In a word, boron enrichment could not offer a sufficient CS for nucleation. Afterwards, the primary $\beta$ Ti grown epitaxially forming columnar dendritic grains. As the bottom of the molten pool completely solidified, the eutectic TiB formed dendritic network structure, which distributed in the interdendritic regions. 
As the solidification proceeded, $G$ changed rapidly. By modeling the heat transfer, Bai et al. [46] and Bermingham et al. [47] concluded that the temperature gradient flattened rapidly during the wire arc additive manufacturing (WAAM) process. Zhao et al. [48] showed a transition from a high growth rate to a low value indicating a stable melt pool profile at the later stage of laser heating during selective laser melting (SLM) of Ti-6Al4V. The DLD molten pool size was between WAAM and SLM. Hence, as the solidification proceeded, the temperature gradient came to be relatively flatter and the Marangoni convection was greatly weakened. Based on this conclusion, the enrichment of boron could be maintained at the tips of columnar dendritic primary $\beta$ Ti grains. Therefore, a much larger overlapping region between the $G$ and $T_{E}$ curve was achieved, and a large enough CS was permitted to offer nucleation of more $\beta$ Ti grains. Subsequently, equiaxed dendritic primary $\beta$ Ti grains nucleated and grew ahead of the tips of dendritic $\beta$ Ti. Hence, a significant transition from columnar to equiaxed grains was achieved. As the temperature dropped to the eutectic point, the eutectic reaction occurred in the remaining liquid, and gave rise to eutectic nano-TiBw and secondary $\beta \mathrm{Ti}$ forming equiaxed network structure, which were shown in Fig. 4. 


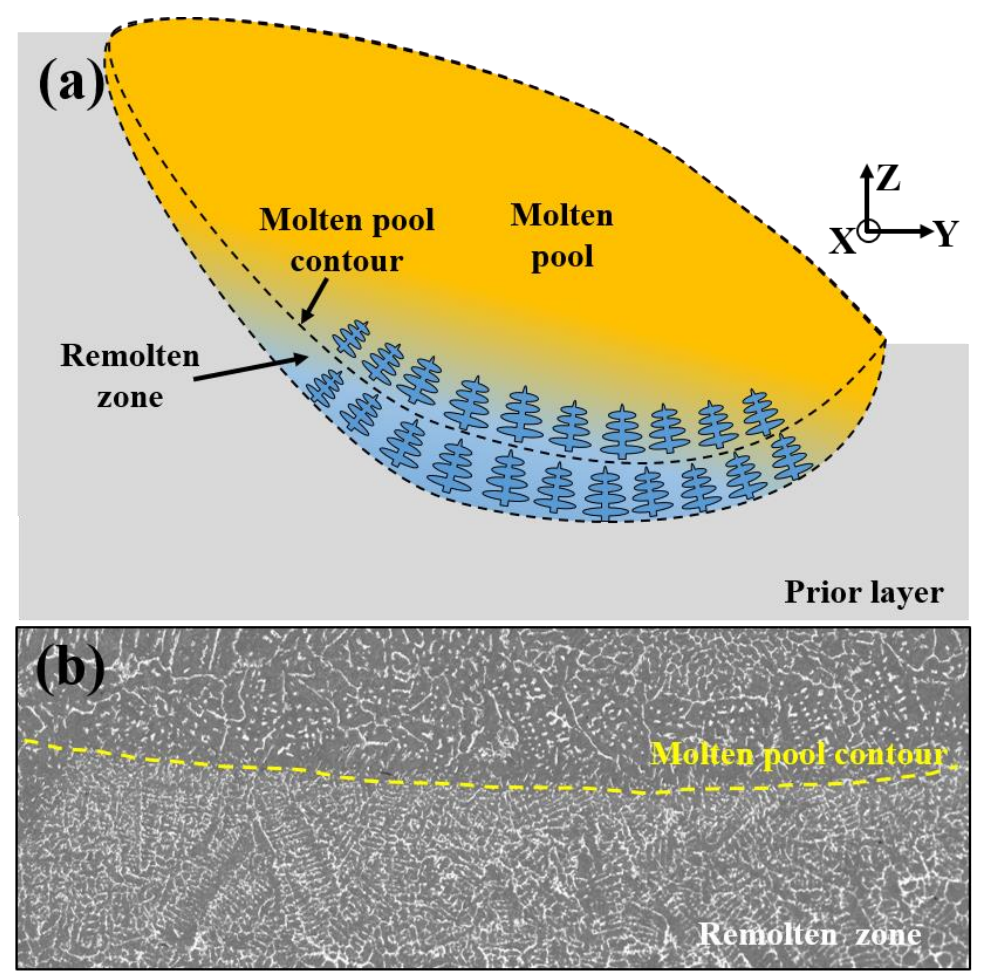

Fig. 10. (a)Schematic of the molten pool and remolten zone; (b)SEM image of the microstructure near molten pool contour.

Recalling the microstructure in Fig. 4c, the molten pool contour was in the middle of the dendritic network structure region, which was enlarged in Fig. 10b. The dendritic network structure above the contour was more discontinuous and sparse than the network below the contour. Fig. 10a schematically presented the detailed formation process of the dendritic structure near the molten pool contour. The remolten zone was heated by the thermal conduction from the molten pool instead of direct laser energy input. The maximum temperature of the remolten zone and the duration time above the melting temperature were both limited. Hence, the viscosity and surface tension of the remolten zone were higher than those of the molten pool. The Marangoni convection was not able to effectively mix the molten pool with the remolten zone and the content of $\mathrm{TiB}$ in the remolten zone was higher than that in the bottom of the molten pool. As the first batch of 
columnar primary $\beta$ Ti occurred in the remolten zone, the original equiaxed network work structure transformed into a dendritic network structure. Besides, the solidification temperature of liquid pure Ti was higher than the Ti-B liquid in the molten pool, resulting in the mismatch of the solidification temperature and an incoherent solidification process. Therefore, a clear contour was observed as the second batch of primary $\beta$ Ti nucleated on the solidified remolten zone surface. It was noted that since a part of the boron was transported elsewhere, the dendritic network structure shows "slender" and discontinuous distribution morphology at the bottom of the molten pool.

The EBSD measurements were conducted both on the equiaxed network structure region and the dendritic network structure region on the YOZ plane. The inverse pole figure (IPF) maps coupling with band contrast (BC) and the corresponding $\{0001\}$ contoured pole figures were shown in Fig. 11 . When the bcc- $\beta$ phase transformed into the hcp- $\alpha / \alpha^{\prime}$ phase, a famous Burgers orientation relationship must be obeyed: $\{1 \overline{1} 0\}_{\beta} / /$ $(0001)_{\alpha},<111>_{\beta} / /<11 \overline{2} 0>_{\alpha}$ [49] and there were 12 equivalent $\alpha$ variants that were possible to form. Inside a parent $\beta$ grain, the $\alpha$ laths of similar inclination tend to have the same crystal orientation [50]. This feature offered a simple method to identify the primary columnar $\beta$ boundary in IPF maps. In Fig. 11b, the dendritic network region, primary $\beta$ grains boundary could be clearly identified, and the texture intensity was calculated to be 4.07. Meanwhile, no primary columnar boundary could be identified in the equiaxed network region (Fig. 11a), and the texture intensity was 2.35 , which was greatly weakened and consistent with the acknowledgment that equiaxed grains did not show preferred crystallographic texture [51]. In recent years, the anisotropy of AMed titanium alloys was 
generally reported due to the preferred $<001>$ orientation of columnar primary $\beta[50,52-$ 54], producing solidification $\alpha$ texture. The attempt to weaken the anisotropy mainly focused on the elimination of columnar primary $\beta$ grains $[47,55,56]$. The existence of strong growth restriction element boron gave rise to more nucleation of primary $\beta$ grains and play an essential role in the columnar to equiaxed transition. Furthermore, the aspect ratio profile of the $\alpha$ grains was counted by Channel 5 software, as shown in Fig. 12. Most of the $\alpha$ grains had an aspect ratio between $1 \sim 3$, and the average aspect ratios in dendritic network region and equiaxed network region were 2.07 and 2.00 respectively, which were far much lower than that of the Widmanstätten or Martensite in AMed CP-Ti $[37,57]$ and indicated a lamellar/acicular to equiaxed transition of $\alpha$ grains.

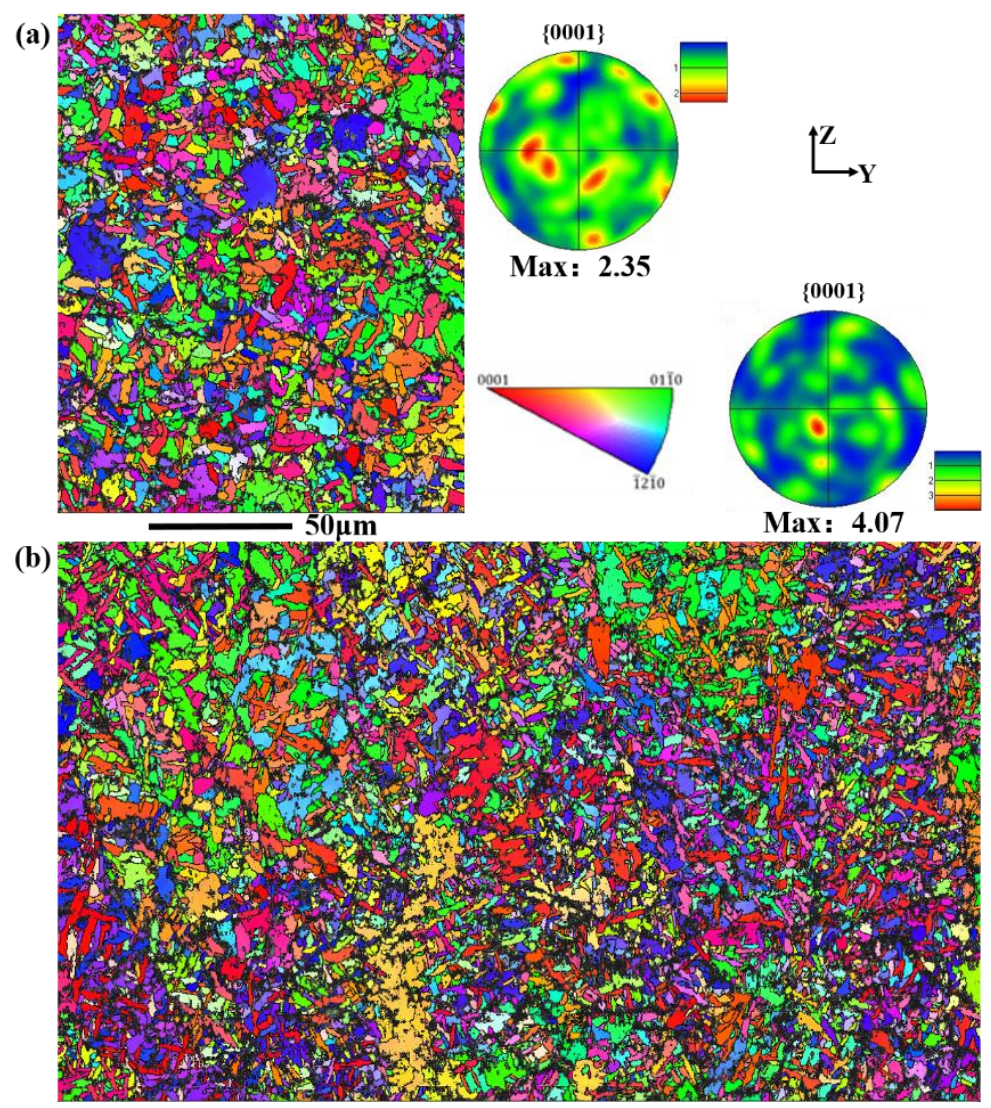

Fig. 11. BC + IPF maps along Z-axis and pole figures of $\alpha$ phase in (a) equiaxed network structure region and (b) dendritic network structure region . 


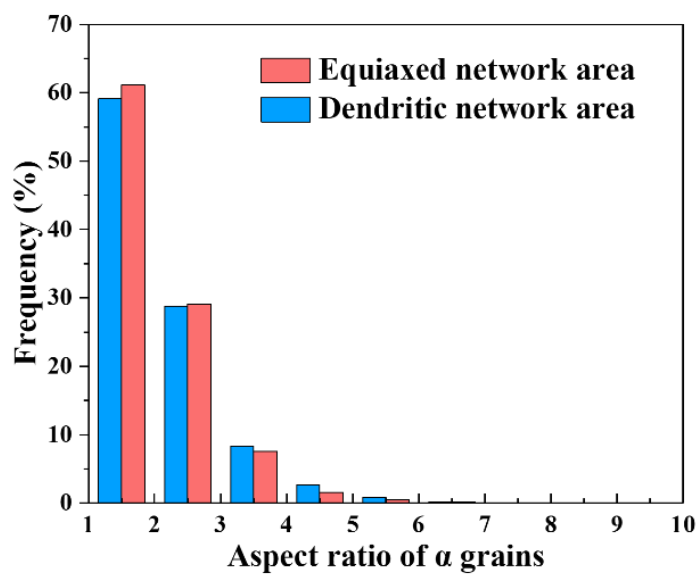

Fig. 12. The aspect ratio profile of $\alpha$ grains.

\subsection{Strengthening mechanism and the role of network structure}

Investigation of the strengthening mechanism of boron modified titanium alloys could be summarized as follows [58]: i) load sharing mechanism; ii) Hall-Petch strengthening; iii) increment in dislocation density due to the different coefficient of thermal expansion between $\mathrm{Ti}$ and $\mathrm{TiB}$; iv) geography necessary dislocations (GNDs) at the Ti-TiB interface; v) Orowan strengthening. Based on a modified Ramakrishnan's approach [59], the yield strength of DLDed TiB-Ti could be written as:

$$
\begin{gathered}
\sigma_{y c}=\sigma_{y m}\left(1+\frac{\Delta \sigma_{H P}}{\sigma_{y m}}\right)\left(1+\frac{\Delta \sigma_{T i B}}{\sigma_{y m}}\right)\left(1+\frac{\Delta \sigma_{d i s}}{\sigma_{y m}}\right) \\
\Delta \sigma_{d i s}=\sqrt{\left(\Delta \sigma_{\text {the }}\right)^{2}+\left(\Delta \sigma_{\text {geo }}\right)^{2}+\left(\Delta \sigma_{\text {Oro }}\right)^{2}}
\end{gathered}
$$

where $\sigma_{y c}$ is the yield strength of the TiB-Ti composite, $\sigma_{y m}$ is the yield strength of the matrix alloy, $\Delta \sigma_{x x}$ is the yield strength increment caused by the corresponding mechanism, and $\Delta \sigma_{d i s}$ represented the strengthening caused by dislocation, including the iii), iv) and v) mechanisms [60].

The classic relationship of Hall-Petch theory could be expressed as: 


$$
\Delta \sigma_{H P}=k_{H P}\left(\frac{1}{\sqrt{d_{2}}}-\frac{1}{\sqrt{d_{1}}}\right)
$$

where $k_{H P}$ is the Hall-Petch constant for Ti, $d_{2}$ is the grain size of DLDed TiB-Ti, $d_{l}$ is the grain size of CP-Ti. Based on the EBSD measurement, the average grain size of the DLDed TiB-Ti sample was estimated to be $1.85 \mu \mathrm{m}$ according to the intercept method.

The strengthening due to the load-bearing effect of TiBw could be expressed as $[9,61]$ :

$$
\Delta \sigma_{T i B}=\sigma_{y m} 0.5 V_{f} \frac{l}{d} C_{0}
$$

where $V_{f}$ is the volume fraction of short-fiber reinforcements, $l / d$ is the average aspect ratio of the whiskers, and $C_{0}$ (ranging from 0 to 1 ) is the fiber orientation factor. For a directional distribution of whiskers, when loaded in the same direction with the whiskers, $C_{0}=1$. For a three-dimensional random array of whiskers (this study), $C_{0}=0.125$ [61].

\begin{tabular}{ccc}
\hline Parameter & Value & Data source \\
\hline$k_{H P}\left(\mathrm{MPa} \cdot \mu \mathrm{m}^{1 / 2}\right)$ & 328 & {$[62]$} \\
$d_{2}(\mu \mathrm{m})$ & $\sim 1.85$ & Measured \\
$d_{l}(\mu \mathrm{m})$ & 0.83 & {$[63]$} \\
$V_{f}$ & $2.5 \mathrm{vol} \%$ & Calculated \\
$l / d$ & $\sim 13.7$ & Measured \\
$C_{0}$ & 0.125 & {$[61]$} \\
\hline
\end{tabular}

Table. 1 The parameters used for calculation

The parameters required for the strengthening calculation was listed in Table. 1. It has been reported that[63], a selective laser melted (SLM) CP-Ti had a yield strength of $524 \mathrm{MPa}$ with a grain size of $0.83 \mu \mathrm{m}$. Using Equation (2), the yield strength increment by grain refinement of the SLMed CP-Ti was calculated as $118 \mathrm{MPa}$, compared with this study. Subtracting the fine grain strengthening increment, SLMed CP-Ti had a yield strength of $406 \mathrm{MPa}$, which is $73 \mathrm{MPa}$ lower than DLDed TiB-Ti. However, the yield 
strength increment of the load-bearing effect of TiBw in this study was calculated as 8.6 $\mathrm{MPa}$, which was far less than the gap of $73 \mathrm{MPa}$. Considering the strengthening mechanism of dislocations could be neglected due to the minor difference of coefficient of thermal expansion between $\mathrm{TiB}$ and $\mathrm{Ti}$ [58], the load-bearing effect of $\mathrm{TiBw}$ was not enough to meet the strengthening effect. Notably, the calculation of $C_{0}$ was conducted under the condition that the TiBw were three-dimensional randomly oriented. Although the orientations of $\mathrm{TiBw}$ were indeed random in this study, the configuration was not homogeneous. Hence, equation (4) could only analyze the load-bearing effect of TiBw, but was short in indicating the extra strengthening effect of the TiBw network.

Subsequently, the in-situ SEM tensile tests were conducted to further understand the strengthening mechanism of the network structure. In the tensile process, the crosshead movement was paused for observing their microstructural evolution. To obtain more information, the in-situ tensile tests were conducted twice with the sample I and II.

Fig. 13a shows the displacement-load curve of the in-situ test sample I. The representative stages were selected, named as "b", "c", and "d" stage. In the early stages, the deformation of the reduced parallel section was homogeneous (Fig. 13b). At the displacement of "b", the slip lines were observed for the first time (Fig. 13b1). The higher magnification images (Fig. 13b2-3) showed that the slip lines were limited by the network structure. At the displacement of "c", a minor necking was observed on the edge of the tensile sample (Fig. 13). The enlarged images showed severe plastic deformation that appeared as surface wrinkles (Fig. 13c1). Multiple microcracks were initiated and propagated across the network structure showing a transgranular fracture mode (Fig. 13c2). Finally, the fracture occurred in the necking area (Fig. 13d), and the side surface 
also confirmed the transgranular fracture phenomenon (Fig. 13d1), multiple microcracks were observed near the fracture surface.

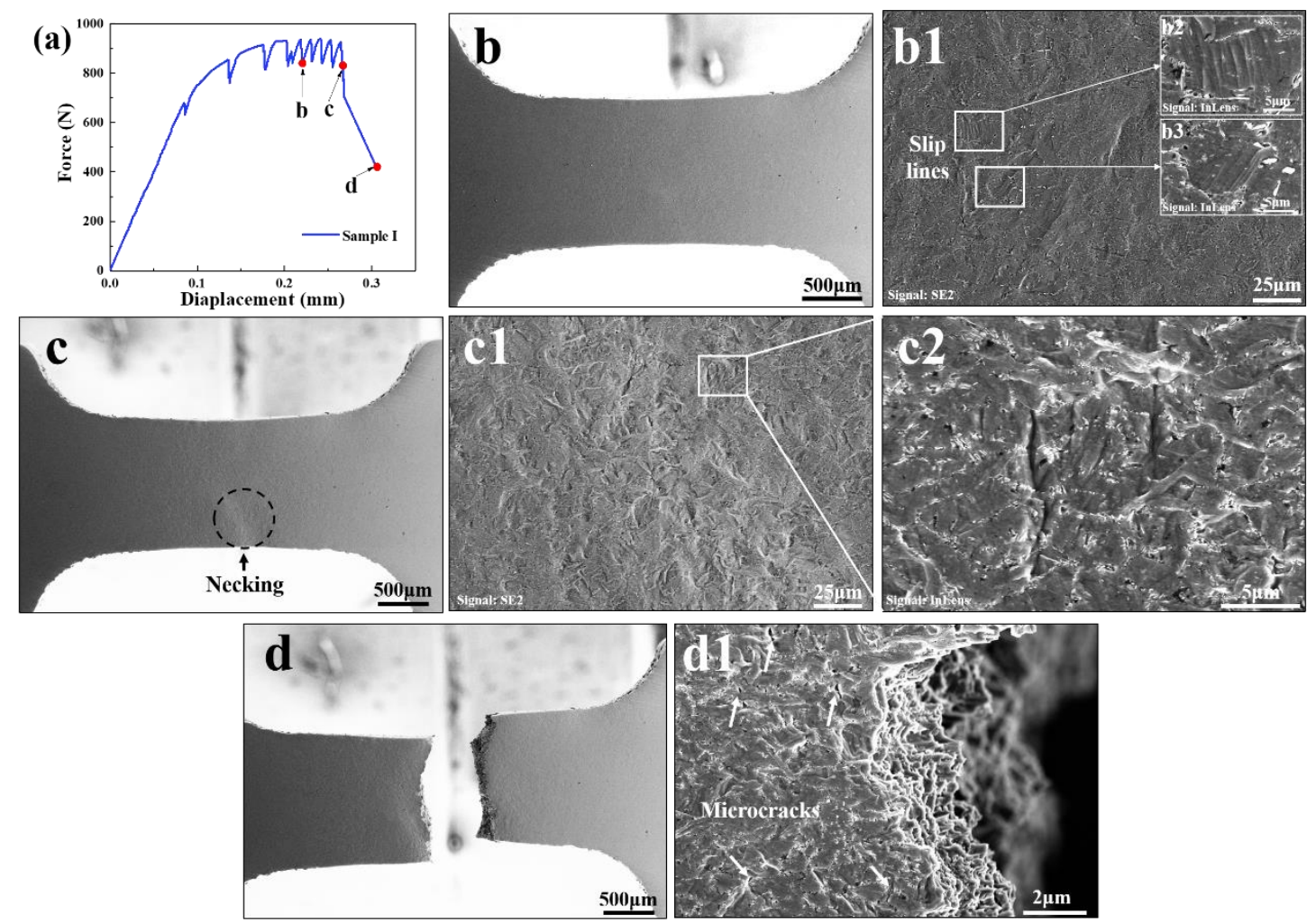

Fig. 13. The in-situ tensile process of sample I. (a)The tensile displacement-force curve of the in-situ test; (b)-(d)the SEM images of the representative stages.

Fig. 14a shows the in-situ tensile displacement-force curve of sample II. At the displacement of "b", a crack was observed nearby the edge of the sample (Fig. 14b). The crack had already completed initiation and propagated along $\sim 45^{\circ}$ to the tensile axis by the moment of detection. The crack consisted of an initial section perpendicular to the tensile axis, a section at $\sim 45^{\circ}$ to the tensile axis propagating throughout the outer side, and a section at $\sim 60^{\circ}$ to the tensile axis propagating into the interior of the sample (Fig. 14b1). The outer section showed the shear fracture characteristic without crack widening and severe plastic deformation, which is the reason for the $45^{\circ}$ fracture. The inner section 
of the crack deflected and hence propagated at $60^{\circ}$ to the tensile axis. The distribution of the TiBw network structure was highlighted by yellow lines in higher magnification images. As the initial section propagated perpendicular to the tensile axis. a segment of the TiBw network was at the location of the crack extension line (marked by a red circle in Fig. 14b2) and made the crack deflect. Afterward, other segments of the TiBw network that were inclined or perpendicular to the crack propagation direction did not deflect the crack. Meanwhile, the crack kept widening. The same deflection effect of the TiB network was also presented in Fig. 14c. As the crack kept developing, significant widening was observed, as well as the blunting of the crack tip (Fig. 14d-e). The Ti matrix showed severe plastic deformation ahead of the crack tip due to the stress concentration effect.
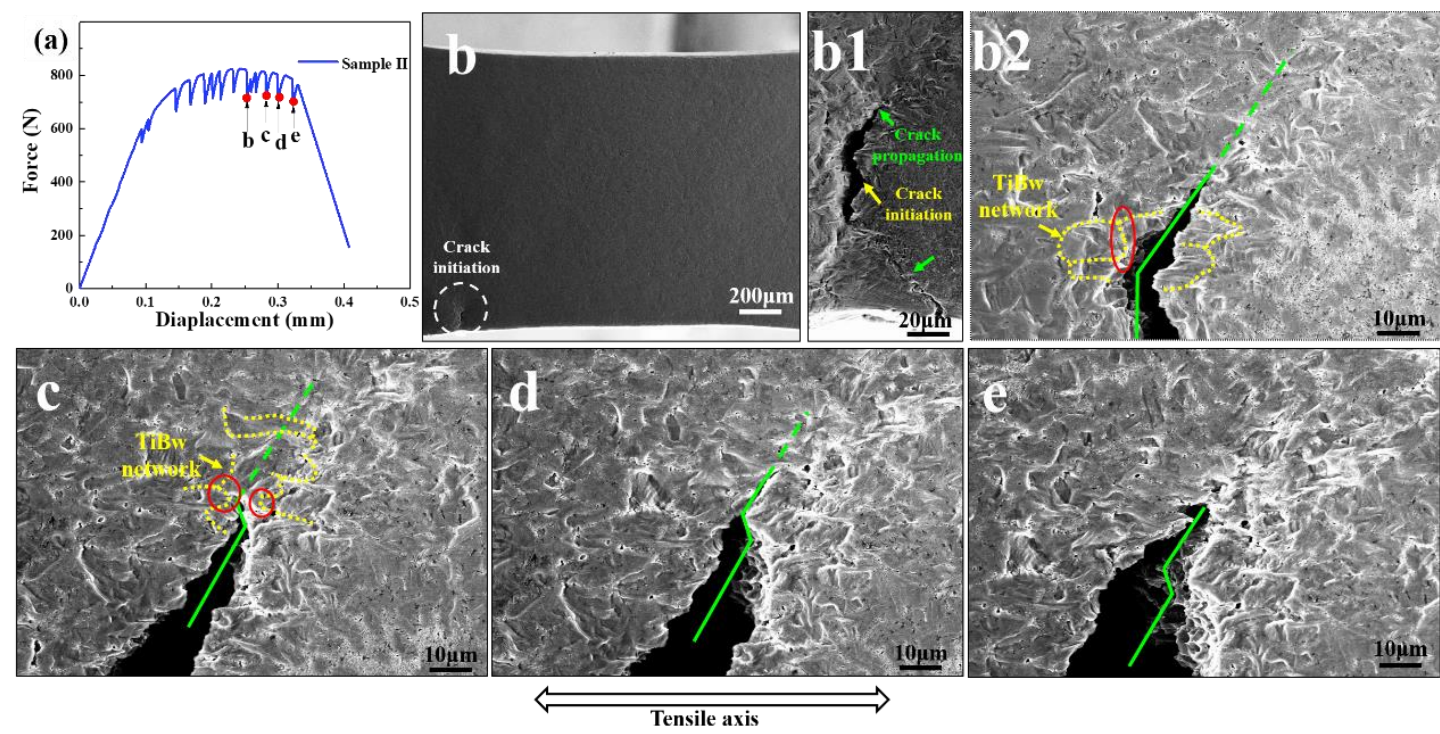

Fig. 14. The in-situ tensile process of sample II. (a)The tensile displacement-force curve of the in-situ test; (b-e) the in-situ observation of crack initiation and propagation

Fig. 15 shows the microstructure of the YOZ section of the fractured tensile test specimen near the fracture surface. The region of the dendritic network was marked by white dashed lines (Fig. 15b). A large number of micro-voids were observed near the 
fracture surface (Fig. 15c-d). All the microvoids initiated in the network structure, most of which located in the network segments that were in the same direction as the stretch axis. Some of the microvoids next to the shear lip were elongated and connected in the shear direction, indicating severe plastic deformation (Fig. 15c). In Fig. 15d, most of the area on the left was the equiaxed network structure, while the small region on the right was the dendritic network structure. The clear trend of decreasing distribution density of the microvoids as the distance from the fracture surface increased was observed. In the dendritic network region, most of the microvoids located in the segments in the same direction as the tensile axis. Meanwhile, some microvoids located in the intersections of the network structure.

Fig. 15e-f illustrated the representative high magnification images of the fractured network structure. In Fig. 15e, the nano-TiBw cluster was parallel to the tensile axis, while the cluster in Fig. 15f was perpendicular to the tensile axis. Since the nano-TiBw were parallel with the tensile axis, the whiskers bore more load than the matrix, leading to the initial breakage of the nano-TiBw. For the case in Fig. 15f, the nano-TiBw could not play the load-bearing role. If the microvoids initiated, the nano-TiBw were still complete but the matrix broke. Fig. $15 \mathrm{~g}$ presented the TEM images of the clustered nano-TiBw. The high-density dislocations distributed in the matrix that was at the end and outer regions of the cluster. Meanwhile, both the dislocation-free region and high-density dislocations were observed in the gaps of the TiB whiskers. As the tensile stress was applied to the sample, the nano-TiBw parallel to the tensile axis would bear much higher stress than the matrix as the interface was clean and well bonded to transfer the stress. However, it was 
reported that the stress concentration caused by the blocking of dislocation motion was the essential reason for the first breakage of TiBw during stretch [11, 64], which was consistent with Fig. 15e. For the nano-TiBw that were not in the direction of stretch or even perpendicular to the tensile axis (Fig. 15e), interface debonding was the main reason for failure, which gave rise to the breakage of the matrix.

Compared with the reported intergranular fracture in the network TiBw reinforced TMCs $[11,65]$, the fracture in this study was a transgranular mode. The difference was mainly attributed to the combination of the cell size of the network structure and the type of matrix alloy. In PM TiBw network TMCs, the cell size was controlled by the diameter of the titanium alloy powder, which was often more than $50 \mu \mathrm{m}$ and far larger than the cell size in this study. Hence, as crack initiated, the finer TiBw network in this study offered a strong limitation of plastic deformation and crack propagation, and it was convinced by the in-situ observation. Hence, although a large number of microvoids initiated, most of them did not develop. Moreover, the pure Ti matrix had a weak strength compared with the Ti6Al4V, hence the matrix could not deflect the crack, leading to the transgranular fracture. 


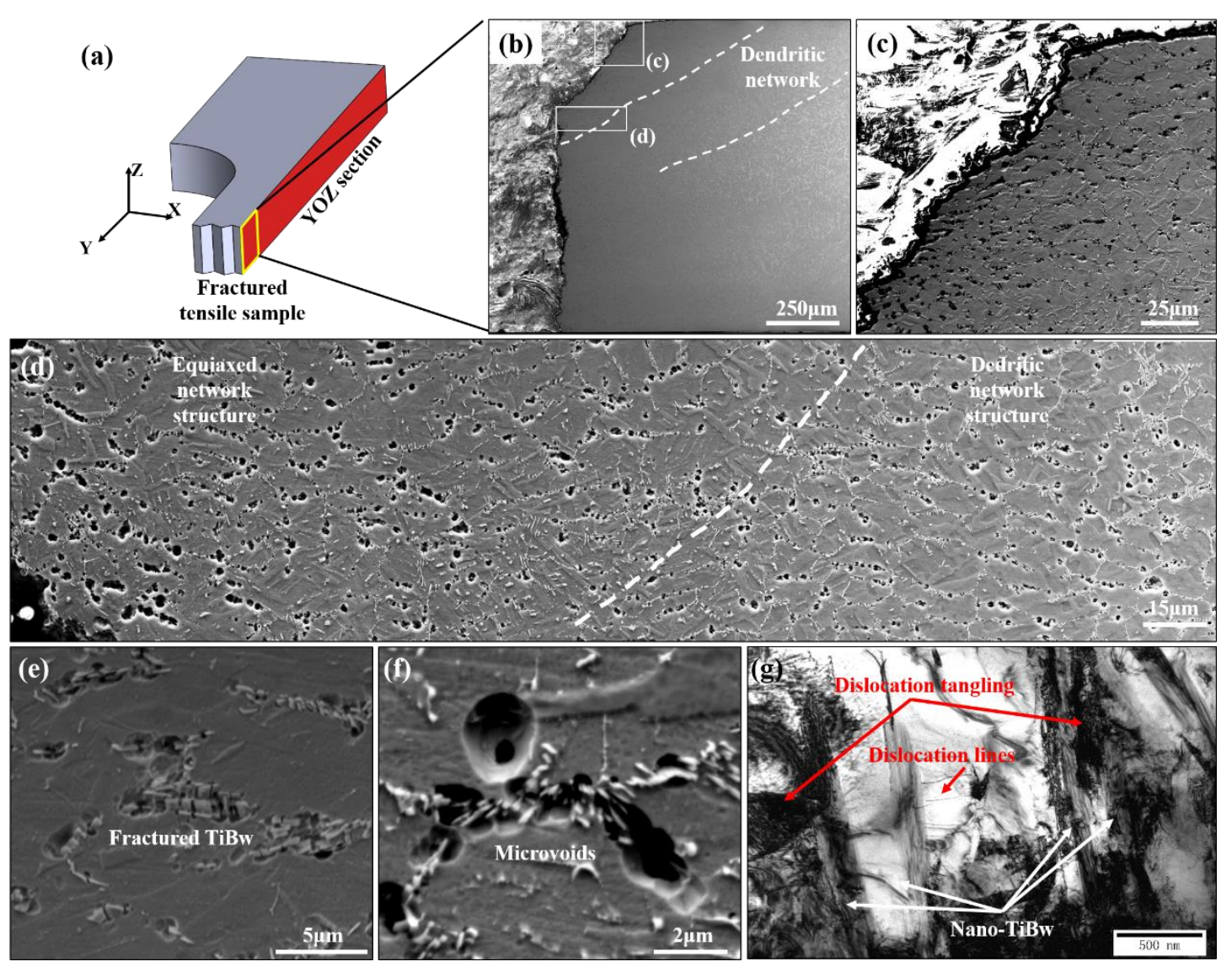

Fig. 15. The SEM images of the microstructure of $Y O Z$ section near the fracture surface: (a)schematic of the fractured tensile sample and observation section; (b-d) the microvoids in different regions; (e-f) the high magnification images of the microvoids and fractured network. (g) TEM image of the dislocations near the nano-TiBw cluster

\section{Conclusion}

In summary, 2.5 vol\% TiB-Ti composite with network distributed nano-sized TiBw was creatively fabricated by direct laser deposition from in-situ embedded TiB titanium matrix composite powder. The main conclusions are as follows:

(1) The microstructure of the DLDed TiB-Ti composite presented the dendritic network structure and the equiaxed network structure at the bottom and in the middle of the molten pool respectively. The network consisted of ultrafine cell size of $\sim 9 \mu \mathrm{m}$ and clustered nano-sized $(\sim 100 \mathrm{~nm})$ TiB whiskers. Both the $\mathrm{B} 27$ and $\mathrm{B}_{\mathrm{f}}$ structure of $\mathrm{TiBw}$ formed in the additive manufacturing process, especially the $\mathrm{B}_{\mathrm{f}}$ 
structure was attributed to the rapid cooling process and eutectic transformation.

(2) The network structure was due to the solidification of primary $\beta \mathrm{Ti}$ and the subsequent eutectic reaction in the remaining liquid. The alternated morphology of the network structure was controlled by the development of constitutional supercooling caused by the enrichment of boron at the solid/liquid interface. The existence of boron in titanium could not only promote the columnar to equiaxed transition of primary $\beta$-Ti grains but also the lamellar/acicular to equiaxed transition of $\alpha$ grains.

(3) The tensile test of the DLDed TiB-Ti sample showed a good combination of strength and ductility with an ultimate tensile strength of $636 \mathrm{MPa}$, and an elongation of $10.6 \%$. Apart from the load-bearing strengthening and Hall-Petch strengthening, the unique configuration of the TiBw network structure was the reason for the superior strength compared with homogeneously reinforced cases.

(4) The TiBw network structure was in-situ observed a significant effect on the limitation of plastic deformation as the slip lines were blocked. Furthermore, the crack propagation was hindered by the network structure, showing as crack deflection and crack tip blunting. The ability of the network structure to limit the plastic deformation was mainly ascribed to the ultrafine cell size, which explained the extra strengthening effect and the significance of fine network structure.

\section{Acknowledgment}

This work was supported by the National Key R\&D Program of China 
(2018YFB1106403), National Natural Science Foundation of China (Grant No: U1602274, 51875349, 51871150, 51821001), the Aeronautical Science Foundation (Grant No: 20173625005), Shanghai Science and Technology Committee Innovation Grant (17JC1402600, 17DZ1120000), the Medical Intersection Project of Shanghai Jiao Tong University (YG2017QN28), the Equipment Pre-Research Foundation (41422010509, 61409230409), the 111 Project (Grant No. B16032), the Laboratory Innovative Research Program of Shanghai Jiao Tong University (Grant No.17SJ-14) and the financial support from China Scholarship Council (CSC) (No 201806235029).

\section{References}

[1] Jiao Y, Huang L, Geng L. Progress on discontinuously reinforced titanium matrix composites. J Alloy Compd. 2018;767:1196-215.

[2] Banerjee D, Williams JC. Perspectives on Titanium Science and Technology. Acta Mater. 2013;61(3):844-79.

[3] Jackson B, Torrens R, Bolzoni L, Yang F, Fry M, Mukhtar A. Additive Manufacturing of Ti-6Al4V with Added Boron: Microstructure and Hardness Modification. Key Eng Mater. 2018;770:165-73.

[4] Zhang L-C, Attar H. Selective Laser Melting of Titanium Alloys and Titanium Matrix Composites for Biomedical Applications: A Review Adv Eng Mater. 2016;18(4):463-75.

[5] Lu W, Zhang D, Zhang X, Wu R, Sakata T, Mori H. Microstructural characterization of TiB in in situ synthesized titanium matrix composites prepared by common casting technique. J Alloy Compd. 2001;327(1):240-7.

[6] Lu W, Guo X, Meng J, Wang F, Wang L, Zhang D. Analysis of the Coupling Effects of TiB Whiskers and TiC Particles on the Fracture Toughness of (TiB + TiC)/TC4 Composites: Experiment and Modeling. Metall Mater Trans A. 2015;46(8):3490-501.

[7] Lu W, Zhang D, Zhang X, Wu R, Sakata T, Mori H. Microstructural characterization of TiC in in situ synthesized titanium matrix composites prepared by common casting technique. J Alloy Compd. 2001;327(1):248-52.

[8] Yang Z, Lu W, Zhao L, Qin J, Zhang D. Microstructure and mechanical property of in situ synthesized multiple-reinforced $(\mathrm{TiB}+\mathrm{TiC}+\mathrm{La} 2 \mathrm{O} 3) / \mathrm{Ti}$ composites. J Alloy Compd. 2008;455(12):210-4.

[9] Guo X, Wang L, Wang M, Qin J, Zhang D, Lu W. Effects of degree of deformation on the microstructure, mechanical properties and texture of hybrid-reinforced titanium matrix composites. Acta Mater. 2012;60(6-7):2656-67.

[10] Huang LJ, Geng L, Li AB, Yang FY, Peng HX. In situ TiBw/Ti-6Al-4V composites with novel reinforcement architecture fabricated by reaction hot pressing. Scr Mater. 2009;60(11):996-9. 
[11] Huang LJ, Geng L, Peng HX, Zhang J. Room temperature tensile fracture characteristics of in situ TiBw/Ti6Al4V composites with a quasi-continuous network architecture. Scr Mater. 2011;64(9):844-7.

[12] Ezugwu E, Wang Z. Titanium alloys and their machinability - a review. Journal of Materials Processing Technology. 1997;68(3):262-74.

[13] Liu S, Shin YC. Additive manufacturing of Ti6Al4V alloy: A review. Mater Des. 2019; $164: 107552$.

[14] Attar H, Ehtemam-Haghighi S, Kent D, Dargusch MS. Recent developments and opportunities in additive manufacturing of titanium-based matrix composites: A review. Int J Mach Tool Manu. 2018;133:85-102.

[15] Herzog D, Seyda V, Wycisk E, Emmelmann C. Additive manufacturing of metals. Acta Mater. 2016;117:371-92.

[16] Attar H, Bönisch M, Calin M, Zhang L-C, Scudino S, Eckert J. Selective laser melting of in situ titanium-titanium boride composites: Processing, microstructure and mechanical properties. Acta Mater. 2014;76:13-22.

[17] Hu Y, Cong W, Wang X, Li Y, Ning F, Wang H. Laser deposition-additive manufacturing of TiBTi composites with novel three-dimensional quasi-continuous network microstructure: Effects on strengthening and toughening. Compos Part B-eng. 2018;133:91-100.

[18] Dong Y, Li Y, Ebel T, Yan M. Cost-affordable, high-performance Ti-TiB composite for selective laser melting additive manufacturing. Journal of Materials Research. 2020;35(15):1922-35.

[19] Wang J, Li L, Lin P, Wang J. Effect of TiC particle size on the microstructure and tensile properties of $\mathrm{TiC} p$ /Ti6Al4V composites fabricated by laser melting deposition. Opt Laser Technol. 2018;105:195-206.

[20] Kang N, Coddet P, Liu Q, Liao H, Coddet C. In-situ TiB/near $\alpha$ Ti matrix composites manufactured by selective laser melting. Addit Manuf. 2016;11:1-6.

[21] Ma C, Zhao J, Cao C, Lin T-C, Li X. Fundamental Study on Laser Interactions With Nanoparticles-Reinforced Metals-Part II: Effect of Nanoparticles on Surface Tension, Viscosity, and Laser Melting. Journal of Manufacturing Science and Engineering. 2016;138(12).

[22] Gu D, Wang H, Zhang G. Selective Laser Melting Additive Manufacturing of Ti-Based Nanocomposites: The Role of Nanopowder. Metall Mater Trans A. 2013;45(1):464-76.

[23] Fereiduni E, Ghasemi A, Elbestawi M. Selective laser melting of hybrid ex-situ/in-situ reinforced titanium matrix composites: Laser/powder interaction, reinforcement formation mechanism, and nonequilibrium microstructural evolutions. Mater Des. 2019:108185.

[24] Li XP, Ji G, Chen Z, Addad A, Wu Y, Wang HW, et al. Selective laser melting of nano-TiB 2 decorated AlSi10Mg alloy with high fracture strength and ductility. Acta Mater. 2017;129:183-93. 
[25] Mahbooba Z, West H, Harrysson O, Wojcieszynski A, Dehoff R, Nandwana P, et al. Effect of Hypoeutectic Boron Additions on the Grain Size and Mechanical Properties of Ti-6Al-4V Manufactured with Powder Bed Electron Beam Additive Manufacturing. JOM. 2016;69(3):472-8.

[26] Yolton C. The pre-alloyed powder metallurgy of titanium with boron and carbon additions. JOM. 2004;56(5):56-9.

[27] Tamirisakandala S, Miracle DB. Microstructure engineering of titanium alloys via small boron additions. Int J Adv Eng Sci Appl Math. 2012;2(4):168-80.

[28] Panda KB, Ravi Chandran KS. Synthesis of ductile titanium-titanium boride (Ti-TiB) composites with a beta-titanium matrix: The nature of $\mathrm{TiB}$ formation and composite properties. Metall Mater Trans A. 2003;34(6):1371-85.

[29] Lu W, Zhang D, Zhang X, Wu R, Sakata T, Mori H. HREM study of TiB/Ti interfaces in a TiBTiC in situ composite. Scr Mater. 2001;44(7):1069-75.

[30] Lu WJ, Xiao L, Geng K, Qin JN, Zhang D. Growth mechanism of in situ synthesized TiBw in titanium matrix composites prepared by common casting technique. Mater Charact. 2008;59(7):9129.

[31] Ravi Chandran KS, Panda KB, Sahay SS. TiBw-reinforced Ti composites: Processing, properties, application prospects, and research needs. JOM. 2004;56(5):42-8.

[32] De Graef M, Löfvander JPA, Levi CG. The structure of complex monoborides in $\gamma$-TiAl alloys with Ta and B additions. Acta Metall. 1991;39(10):2381-91.

[33] Kooi BJ, Pei YT, De Hosson JTM. The evolution of microstructure in a laser clad TiB-Ti composite coating. Acta Mater. 2003;51(3):831-45.

[34] Sabahi Namini A, Azadbeh M, Shahedi Asl M. Effect of TiB 2 content on the characteristics of spark plasma sintered Ti-TiB w composites. Adv Powder Technol. 2017;28(6):1564-72.

[35] Huang LJ, Wang S, Geng L, Kaveendran B, Peng HX. Low volume fraction in situ (Ti5Si3+Ti2C)/Ti hybrid composites with network microstructure fabricated by reaction hot pressing of Ti-SiC system. Compos Sci Technol. 2013;82:23-8.

[36] Huang LJ, Wang S, Dong YS, Zhang YZ, Pan F, Geng L, et al. Tailoring a novel network reinforcement architecture exploiting superior tensile properties of in situ TiBw/Ti composites. Mater Sci Eng A. 2012;545:187-93.

[37] Zhang Y, Wei Z, Shi L, Xi M. Characterization of laser powder deposited Ti-TiC composites and functional gradient materials. Journal of Materials Processing Technology. 2008;206(1-3):438-44.

[38] Imayev V, Gaisin R, Gaisina E, Imayev R, Fecht HJ, Pyczak F. Effect of hot forging on microstructure and tensile properties of Ti-TiB based composites produced by casting. Mater Sci Eng A. 2014;609:34-41. 
[39] Li L, Wang J, Lin P, Liu H. Microstructure and mechanical properties of functionally graded TiC p /Ti6Al4V composite fabricated by laser melting deposition. Ceram Int. 2017;43(18):16638-51.

[40] Khairallah SA, Anderson AT, Rubenchik A, King WE. Laser powder-bed fusion additive manufacturing: Physics of complex melt flow and formation mechanisms of pores, spatter, and denudation zones. Acta Mater. 2016;108:36-45.

[41] Cai C, Radoslaw C, Zhang J, Yan Q, Wen S, Song B, et al. In-situ preparation and formation of TiB/Ti-6Al-4V nanocomposite via laser additive manufacturing: Microstructure evolution and tribological behavior. Powder Technol. 2019;342:73-84.

[42] Tamirisakandala S, Bhat RB, Tiley JS, Miracle DB. Grain refinement of cast titanium alloys via trace boron addition. Scr Mater. 2005;53(12):1421-6.

[43] Maxwell I, Hellawell A. A simple model for grain refinement during solidification. Acta Metall. 1975;23(2):229-37.

[44] Okamoto H, Okamoto H. Phase diagrams for binary alloys: ASM international Materials Park, $\mathrm{OH} ; 2000$.

[45] Bermingham MJ, McDonald SD, StJohn DH, Dargusch MS. Beryllium as a grain refiner in titanium alloys. J Alloy Compd. 2009;481(1-2):L20-L3.

[46] Bai X, Colegrove P, Ding J, Zhou X, Diao C, Bridgeman P, et al. Numerical analysis of heat transfer and fluid flow in multilayer deposition of PAW-based wire and arc additive manufacturing. Int J Heat Mass Transf. 2018;124:504-16.

[47] Bermingham MJ, StJohn DH, Krynen J, Tedman-Jones S, Dargusch MS. Promoting the columnar to equiaxed transition and grain refinement of titanium alloys during additive manufacturing. Acta Mater. 2019;168:261-74.

[48] Zhao C, Fezzaa K, Cunningham RW, Wen H, De Carlo F, Chen L, et al. Real-time monitoring of laser powder bed fusion process using high-speed X-ray imaging and diffraction. Sci Rep. 2017;7(1):3602.

[49] Wang SC, Aindow M, Starink MJ. Effect of self-accommodation on $\alpha / \alpha$ boundary populations in pure titanium. Acta Mater. 2003;51(9):2485-503.

[50] Simonelli M, Tse YY, Tuck C. On the Texture Formation of Selective Laser Melted Ti-6Al-4V. Metall Mater Trans A. 2014;45(6):2863-72.

[51] Todaro CJ, Easton MA, Qiu D, Zhang D, Bermingham MJ, Lui EW, et al. Grain structure control during metal 3D printing by high-intensity ultrasound. Nat Commun. 2020;11(1):142.

[52] de Formanoir C, Michotte S, Rigo O, Germain L, Godet S. Electron beam melted Ti-6Al-4V: Microstructure, texture and mechanical behavior of the as-built and heat-treated material. Mater Sci Eng A. 2016;652:105-19. 
[53] Carroll BE, Palmer TA, Beese AM. Anisotropic tensile behavior of Ti-6Al-4V components fabricated with directed energy deposition additive manufacturing. Acta Mater. 2015;87:309-20.

[54] Yang Y, liu YJ, Chen J, Wang HL, Zhang ZQ, Lu YJ, et al. Crystallographic features of $\alpha$ variants and $\beta$ phase for Ti-6Al-4V alloy fabricated by selective laser melting. Mater Sci Eng A. 2017;707:54858.

[55] Xue A, Lin X, Wang L, Wang J, Huang W. Influence of trace boron addition on microstructure, tensile properties and their anisotropy of Ti6Al4V fabricated by laser directed energy deposition. Mater Des. 2019;181.

[56] Bermingham MJ, McDonald SD, Dargusch MS. Effect of trace lanthanum hexaboride and boron additions on microstructure, tensile properties and anisotropy of Ti-6Al-4V produced by additive manufacturing. Mater Sci Eng A. 2018;719:1-11.

[57] Amado JM, Rodríguez A, Montero JN, Tobar MJ, Yáñez A. A comparison of laser deposition of commercially pure titanium using gas atomized or Ti sponge powders. Surf Coat Technol. 2019;374:253-63.

[58] Singh G, Ramamurty U. Boron modified titanium alloys. Prog Mater Sci. 2020;111.

[59] Ramakrishnan N. An analytical study on strengthening of particulate reinforced metal matrix composites. Acta Mater. 1996;44(1):69-77.

[60] Humphreys F. Mechanical and physical behavior of metallic and ceramic composites. the 9th Riso International Symposium on Metallurgy and Materials Science1988. p. 51.

[61] Fukuda H, Chou T-W. A probabilistic theory of the strength of short-fibre composites with variable fibre length and orientation. J Mater Sci. 1982;17(4):1003-11.

[62] Kohn DH, Ducheyne P. Tensile and fatigue strength of hydrogen-treated Ti-6Al-4V alloy. J Mater Sci. 1991;26(2):328-34.

[63] Pan D, Zhang X, Hou X, Han Y, Chu M, Chen B, et al. TiB nano-whiskers reinforced titanium matrix composites with novel nano-reticulated microstructure and high performance via composite powder by selective laser melting. Mater Sci Eng A. 2021;799:140137.

[64] Xiang J, Han Y, Huang G, Le J, Chen Y, Xiao L, et al. Microstructural evolution in titanium matrix composites processed by multi-pass equal-channel angular pressing. J Mater Sci. 2019;54(10):793142.

[65] Huang L, Wang L, Qian M, Zou J. High tensile-strength and ductile titanium matrix composites strengthened by TiB nanowires. Scr Mater. 2017;141:133-7. 